\title{
Factors Influencing the Decision to Choose Information Technology Preparatory Studies in Secondary Schools: An Exploratory Study in Regional/Rural Australia
}

\author{
Glen Van Der Vyver, Debbie Crabb, and Michael S Lane \\ University of Southern Queensland, Toowoomba, Australia
}

\section{vandervy@usq.edu.au dcrabb@usq.edu.au lanem@usq.edu.au}

\begin{abstract}
The career paths of students are influenced and shaped by the subject choices that are made in the final years of secondary schooling. This paper presents the findings of an empirical study that identified the key factors influencing the decision of rural / regional Australian students to choose or not choose to study Information Processing and Technology. The findings revealed that career oriented, extrinsic factors play an important role in motivating the selection of I.P.T. at school and, by implication, information technology at university. There are few apparent gender differences but there is limited evidence to suggest that males may be more influenced by extrinsic motivators and females by intrinsic motivators. Although the factors used in the study were initially identified largely via informal processes, they all appear to influence the decision to take I.P.T. The focus on career-related factors and the instrumentality of taking I.P.T. could explain the drop-off in students taking the subject. This has potentially significant implications as regards the future supply of good information technology professionals.
\end{abstract}

Keywords: IT Education, skills shortage, high school subject choice, IT careers.

\section{Introduction}

Subjects chosen in the final two years of secondary school have a strong influence on the overall career choices of students and the choices they make about tertiary education. In the last few years, following a downward trend in the I.T. industry, there has been a significant decline in the number of students selecting I.T. or a related subject as a major in undergraduate degrees at Australian universities. Beyond the obvious implications for information technology departments at universities, the smaller pool of students choosing information technology in all likelihood means that a proportion of the most capable students are lost to the field. This comes at a time when employers are demanding high calibre graduates with strong academic records and the skills necessary to meet the challenges of a changing I.T. workplace. Furthermore, a turnaround in demand

Material published as part of this journal, either on-line or in print, is copyrighted by Informing Science. Permission to make digital or paper copy of part or all of these works for personal or classroom use is granted without fee provided that the copies are not made or distributed for profit or commercial advantage AND that copies 1) bear this notice in full and 2) give the full citation on the first page. It is permissible to abstract these works so long as credit is given. To copy in all other cases or to republish or to post on a server or to redistribute to lists requires specific permission from the publisher at Publisher@InformingScience.org could find the industry again facing significant skills shortages.

By identifying the factors that influence and shape students decision to choose I.P.T. (Information Processing and Technology) the tertiary sector can, in cooperation with secondary schools, formulate strategies to in- 
crease the number of high quality students choosing the subject.

This research examines attitudes to I.P.T. (Information Processing and Technology) and the reasons for choosing this subject in a group of secondary students at schools in a large regional centre in Queensland. The vast majority of these students come from rural / regional Australia. This research will provide information and indicate solutions to decision makers in school administration and curriculum design, and assist them in making informed choices when developing curriculum paths for senior students. Knowledge of the factors which influence students to choose I.P.T. and the perceptions of students during their course of study will enable teachers to promote I.P.T. in a manner which would enhance student interest and participation. From a policy perspective, it is essential that some of the most capable students, male and female, in regional Australia are attracted to I.P.T. in school and I.T. at university. It is from this group that many of the innovators and entrepreneurs will come that will be needed to keep regional Australia viable in the global economy.

\section{Background}

There has been a significant decline in the number of students applying for admission to Information Technology courses at Australian universities in 2003/2004. The Australian Computer Society is of the opinion that this has serious adverse implications for the industry ("Students shun IT in downturn," 2002). There has been a national decrease of 25-30\% in applications to study I.T. at tertiary level. Although the information technology sector is in a downturn at present, the smaller numbers of students enrolling in I.T. degree programs could indicate serious skills shortages when the economy rebounds.

There have been relatively few studies of factors motivating subject choice at secondary level, particularly in Australia. Preece (1983) argued that the curriculum choice is more important than variations in quality of instruction while Taylor Fitz-Gibbon (1999, p.218) suggested that: Which subjects were studied may have greater impact on the long-term knowledge of students and may have more consequences for their subsequent life chances, than how well the subjects were stud$i e d$. While much of the research in this area has focused on 'shortage' areas such as mathematics and science, it could be argued that information technology is another subject area that is likely to have a significant impact on the life chances of the student who makes the appropriate choice. Despite the current downturn in I.T., the occupation has a long history of delivering life chances.

Although students enrolling in information technology courses at universities in Australia come from a large variety of school and work settings, a significant number of new entrants have historically come from recent school leavers who have studied information technology subjects to year 12 level. There are indications that, even during the I.T. boom, the numbers of students choosing to study I.P.T. to year 12 in Queensland have been relatively disappointing. As knowledge of the downturn becomes more widely disseminated in the general population, the numbers are likely to come under even more pressure in 2004.

Within the context of rural / regional Australia, information technology has provided excellent opportunities for many people who would otherwise have struggled to find work. Admittedly, this has usually resulted in migration to urban centres but some of the skills have remained in regional centres, helping local economies survive and even prosper. In recent years, government and industry has also been involved in a number of initiatives aimed at fostering rural renewal via I.T. such as the 'Networking the Nation' program. These programs have funded many large I.T. projects in regional and rural communities in Australia.

The I.T. downturn and the apparent decline in interest amongst potential students is therefore potentially more serious in regional / rural Australia than in urban centres. An important source of 
career prospects is now challenged and various programmes aimed at regional development via I.T. may be compromised in future. Students who have completed their schooling in regional Australia are more likely to work in these areas than their urban counterparts. They also have a deeper knowledge and insight into the problems of regional Australia.

\section{Subject Choice in Secondary School: A Complex Process}

Studies in the UK and USA, for example the work by Preece and Taylor Fitz-Gibbon mentioned above, attest to the importance of subject choice at secondary school. Studies in Australia have validated these findings in the Australian context (Ainley, Jones, \& Navaratnam, 1990; McBryde 1991; Warton and Cooney 1997). Ainley et al. (1990, p.1) argue that the subjects chosen by students in the senior secondary years are widely considered to be important in shaping educational and occupational futures. McBryde (1991) examined the correlation between subject choice, OP (the overall indicator of performance) and tertiary offers received came to the conclusion that the subject select decisions pupils in Queensland make at the beginning of year 11 have important consequences in terms of the offers that will be received (or not) for tertiary entry upon completion of year 12 .

McBryde (1991) raises the question whether education is delivering an adequate return on investment. This 'rate of return' can be measured in a variety of ways such as acceptance into higher education and employability. While such measures could address important issues relating to efficacy and accountability, they have serious implications for teachers. Clearly, choosing the 'right' subjects will have a positive influence on return on investment. Should teachers be exerting influence on students to take subjects which are likely to offer a positive return on investment, in terms of national and individual resources expended?

A number of Australian studies have also examined the influence of a variety of factors on subject choice. Campbell and McMeniman (1982) found that location, size and type of school attended and socio-economic status were important factors influencing subject choice. Ainley, Robinson, Harvey-Beavis, Elsworth, and Fleming (1994, p. 12) found that school structures (the curriculum and timetabling) were shown to shape the choice of school subjects. Lee (1993) argued that an important determinant of subject choice is simply what subjects are available to choose from. For a few, this could be restrictive, for example in the case of a rural school that is not able to offer a wide range of subjects. For the majority of students, however, the opposite is true. As students move into their final years of schooling, they are often confronted by a bewildering array of available subjects - in some cases, upwards of eighty. Even those students whose choices are restricted by geography usually have access to sophisticated alternative delivery mechanisms, for example Queensland's highly developed distance learning network.

Given the alternatives available, making subject decisions is clearly very difficult for many students. But, how does the average student obtain information about the choices available? Would the student's local school provide equal amounts of information about all subjects? Might certain subjects be favoured? Would a school inform a student about interesting options available via distance learning when that school could lose funding by virtue of the act of informing the student?

Subject choice is often related to career choice and research tends to follow either a psychological or a sociological approach. Research with a sociological focus typically considers structural factors. Furlong and Cartmel (1995), for example, argued that available opportunities (beyond merely the subjects available) play an important role in the development of occupational and educational aspirations. Psychological approaches are more interested in the decision-making ele- 
ments of subject and career choices. Psychological models propose a rational approach to career decision making, emphasizing process rather than choice. The process might involve goals setting, generating and assessing options, fact collection, brainstorming the potential effect of choices, and a review of choices before implementation (Mann \& Harmon, 1988; Ormond \& Luszcz, 1991).

We argue that the career decision process is more complex than the psychological or sociological approach is capable of explaining. It encompasses sociological, psychological and information gathering elements. When people need to make decisions, they seek information. This information may be sought from formal sources but people also use informal networks, for example friends, family and associates. People vary according to the way in which they seek information (style) and the way in which this information is processed (heuristics). When viewed in terms of information seeking, many elements of the subject selection process are not rational. Previous research on gender differences in the process of subject selection reinforces this point. Warton and Cooney (1997) argued that the relationships of females are more intimate than those of males. Furthermore, females are usually better integrated into the school environment and have typically formed better networks with other students and teachers. Thus, females are likely to seek information from different sources than males and, where the sources converge, the level of importance attached to an information source is likely to differ.

\section{Research Questions and Method}

There has been relatively little focused work on the specific variables influencing subject choice in general and less on the decision to choose I.P.T. in particular.

This study seeks to identify a number of variables that influence choice and evaluate their impact. The study is concerned with the perceptions and attitudes of students regarding their decision to study I.P.T. during their senior school years. For this research we adopt a sociological (structural) approach as a point of departure. While subject choice will not be examined from a psychological (process) approach, the influence of cognitive processes related to information seeking / processing will be examined in subsequent research.

A series of informal interviews was conducted with high school teachers, pupils and parents. The participants in these interviews were asked to identify variables they considered important when students are choosing their senior secondary school subjects. Variables identified by this informal interview process as influencing students' decision to choose a particular subject included: parents, guidance officer, teachers, friends, future career, knowledge, reputation of the teacher and effect on OP (entry level score required for university entry).

The list of variables identified in the informal interview process were tested and refined in a pilot survey which was conducted with a group of Year 12 students who were attending a promotional function conducted by the university. While a rigorous sampling procedure was not used with this group, participants from a significant number of schools were invited.

While the literature indicates that there are potentially a significant number of other variables, many of which we may not even be aware, it was decided that a parsimonious instrument would be most suitable. The pilot survey identified the following eight (sometimes surprising) items as relevant to students' decision to choose I.P.T.

- Advice from and discussion with parents.

- Advice from school guidance officer / teachers.

- Subjects being selected by friends. 
- The line/s on which the subject appeared on the selection form.

- Future career choice.

- Knowledge of topics covered in the subject.

- Reputation of the teacher of the subject.

- Influence of taking IPT on future OP.

This study seeks to establish whether the eight variables named above do influence the choice of I.P.T. as a secondary subject and whether there is evidence to suggest some of the variables are acting in concert. We are also interested in the influence of gender on subject choice.

The following questions are examined:

- Is there evidence to suggest that the eight variables are valid predictors of the choice of IPT as a senior secondary subject?

- Is there evidence to suggest that the eight variables are equally important as predictors of the choice of IPT as a senior secondary subject?

- Is there evidence to suggest that the variables identified as most important can help to explain the drop-off in number of students choosing to study information systems / computer science at tertiary level?

- Is there evidence to suggest that there are gender differences as regards the variables which influence the choice of I.P.T. as a senior secondary subject?

\section{Results}

All year 11 and 12 I.P.T. students present on the day of survey at nine schools in Toowoomba were surveyed. These schools constitute a good mix between public and private education institutions. The survey instrument was administered by one of the researchers to one class of students at a time. A five point Likert scale was used, where 1 indicates a high level of influence and $5 \mathrm{a}$ low level of influence for a particular variable. In total, 302 students were surveyed, 229 males and 74 females. Because we were surveying a relatively large number of students and were allocated a small time slot, it was important to use a short questionnaire in this first phase of the study.

Table 1 shows descriptive statistics each of the factors thought to influence student decisions to study I.P.T. in years 11 and 12, sorted in descending order of influence. For each variable, the levels of influence are:

1 Major influence.

2 Significant influence.

3 Some influence.

4 Minor influence.

5 No influence. 
Table 1 - Influencing Factors: Descriptive Statistics

\begin{tabular}{|l|l|l|l|l|l|}
\hline & $\mathrm{N}$ & Minimum & Maximum & Mean & $\begin{array}{l}\text { Std. Devia- } \\
\text { tion }\end{array}$ \\
\hline Career & 301 & 1 & 5 & 2.43 & 1.243 \\
Teacher Reputation & 301 & 1 & 5 & 2.72 & 1.268 \\
Topics & 300 & 1 & 5 & 2.83 & 1.243 \\
O P Score & 301 & 1 & 5 & 2.84 & 1.168 \\
Line & 301 & 1 & 5 & 3.02 & 1.287 \\
Guidance Officer & 303 & 1 & 5 & 3.08 & 1.256 \\
Advice & 302 & 1 & 5 & 3.17 & 1.265 \\
Friends & 303 & 1 & 5 & 3.23 & 1.249 \\
Parent Advice & 293 & & & & \\
Valid N (listwise) & & & & \\
\hline
\end{tabular}

It can be seen that all the variables have some degree of influence on student decisions to study I.P.T. No variable has very low or very high levels of influence but a group of variables tends towards high levels of influence while another group tends towards a discernable level of influence. None of the variables seems to have little influence. The dispersion of scores is also remarkably similar across the variables. It is interesting to note that the items that are most strongly related to rational decision making dominate, while items relating to advice from others are weaker, but still significant. The relative strength of the apparently arbitrary variables 'Line' is also noteworthy.

Although the small number of variables involved does not suggest a factor analysis would be useful for the purposes of data reduction, the apparent grouping of variables apparent in Table 1 does

Table 2 - Principal Component Analysis with Varimax Rotation

\begin{tabular}{|l|l|l|l|}
\hline \multirow{2}{*}{} & \multicolumn{3}{l|}{ Component } \\
\cline { 2 - 4 } & 1 & 2 & 3 \\
\hline Career & .762 & -.025 & -.056 \\
Friends & -.143 & .012 & .729 \\
Line & .057 & .086 & .698 \\
O P Score & .621 & .008 & .197 \\
Parent Advice & .009 & .810 & .113 \\
Guidance Officer Ad- & .064 & .835 & .103 \\
vice & .272 & .277 & .555 \\
Teacher Reputation & .770 & .129 & -.065 \\
Topics & &
\end{tabular}


suggest that a factor analysis would be useful to confirm that groups of factors are acting in concert.

A correlation matrix reveals a perhaps disappointing level of internal cohesion but does reinforce the notion that the variables are operating in clusters.

A principal component analysis with varimax rotation (see Table 2) supports the idea that the variables are operating in smaller clusters. Thus, career, predicted OP score and topic in the subject load significantly on factor 1 , guidance teacher and parent advice load significantly on factor 2 and friends, while teacher reputation and the line on the selection form on which the subject appears load significantly on factor 3 .

Males appear to be more influenced by a number of the variables of interest (Table 3): these are career, line, and the topics in the subject. Females are more influenced than males by friends, OP score and teacher reputation. The scores of the females exhibit a higher level of dispersion but this may be influenced by the fact that there were significantly more male than female students involved in study.

Table 3 - Gender Differences

\begin{tabular}{|l|ll|l|l|l|}
\hline & Gender & $\mathrm{N}$ & Mean & $\begin{array}{l}\text { Std. } \\
\text { Deviation }\end{array}$ \\
\hline Career & 1 & male & 228 & 2.33 & 1.195 \\
Friends & 2 & female & 72 & 2.72 & 1.324 \\
& 1 & male & 228 & 3.21 & 1.264 \\
Line & 2 & female & 73 & 3.04 & 1.252 \\
& 1 & male & 227 & 2.96 & 1.275 \\
O P Score & 2 & female & 73 & 3.21 & 1.301 \\
& 1 & male & 227 & 2.87 & 1.129 \\
Parent Advice & 1 & male & 73 & 2.71 & 1.264 \\
& 2 & female & 73 & 3.21 & 1.239 \\
Guidance Offi- & 1 & male & 229 & 3.26 & 1.280 \\
cer Advice & 2 & female & 73 & 3.08 & 1.212 \\
Teacher Repu- & 1 & male & 228 & 2.79 & 1.382 \\
tation & 2 & female & 72 & 2.49 & 1.311 \\
Topics & 1 & male & 227 & 2.76 & 1.244 \\
& 2 & female & 72 & 3.06 & 1.232 \\
\hline
\end{tabular}

It is surprising to note that only one of the variables (career) reveals a significant difference between males and females where $\alpha=0.05$ while a second variable (topics) is significant with $\alpha=$ 0.10. (See Table 4.). 
Table 4 - Tests for the difference between means based on gender

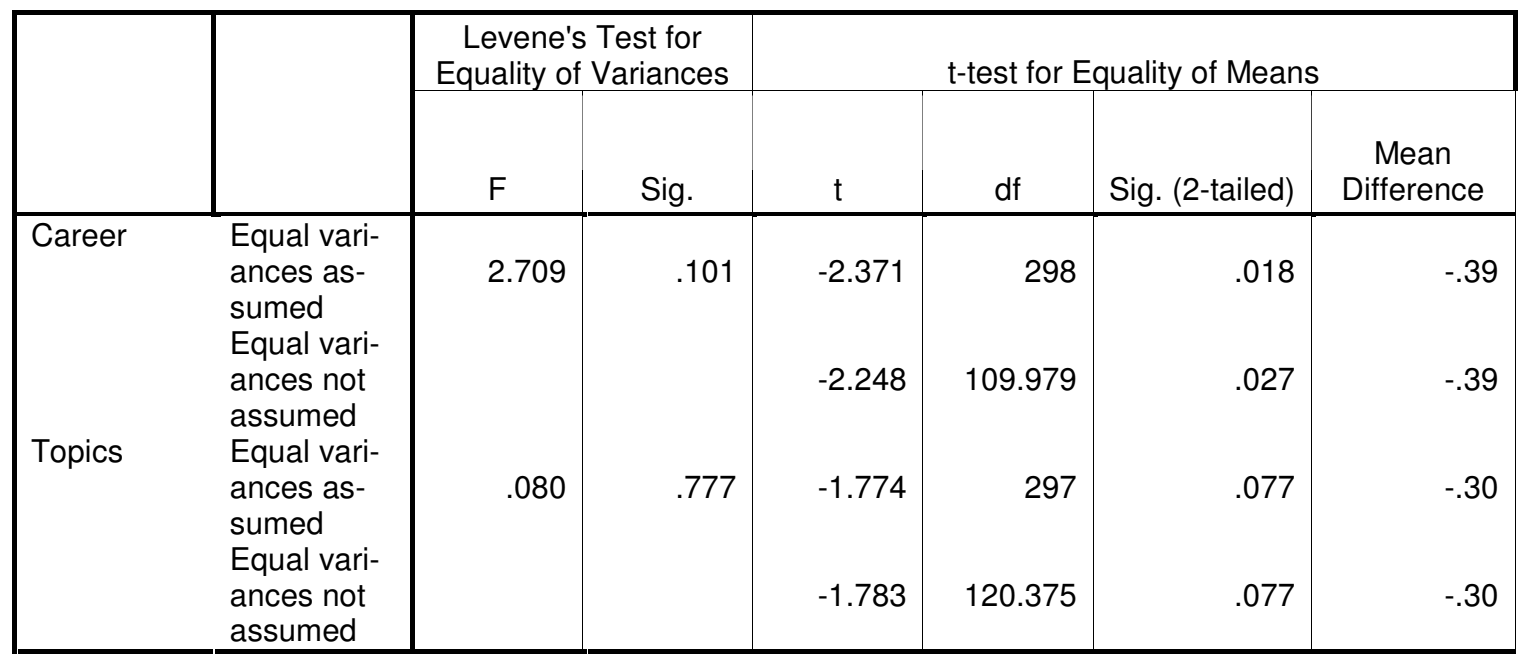

\section{Conclusions and Implications}

Based on our findings we conclude that the variables identified during our informal analysis of reasons for choosing I.P.T. in year 11 and 12 do indeed appear to influence students when making this important decision. Although the intercorrelations across all variables were rather disappointing, three groups of variables emerged and each variable was accommodated within one of the three groups.

We present a preliminary research model of the key variables influencing students decision to choose I.P.T. as a final years subject in secondary school in rural / regional Australia (see Figure $1)$..

In terms of our stated questions, we find the following:

- There is evidence to suggest that the eight variables are valid predictors of the choice of I.P.T. as a senior secondary subject. None of the eight variables were insignificant in terms of their influence.

- There was substantial variation as regards the extent of influence of the eight variables.

- We believe that the results of this study do provide some insights into the drop-off in numbers of students enrolling in information systems / computer science courses. We will examine this in more detail below.

- Although the results did show some gender differences, their impact was limited.

The study suggests that students in rural / regional Australia do not mirror their urban counterparts when it comes to what influences them to take I.P.T. at secondary school. A striking example is the influence of friends, especially amongst female students. While the female students were more influenced by friends than the male students, the level of influence was much lower than previous research would suggest. 


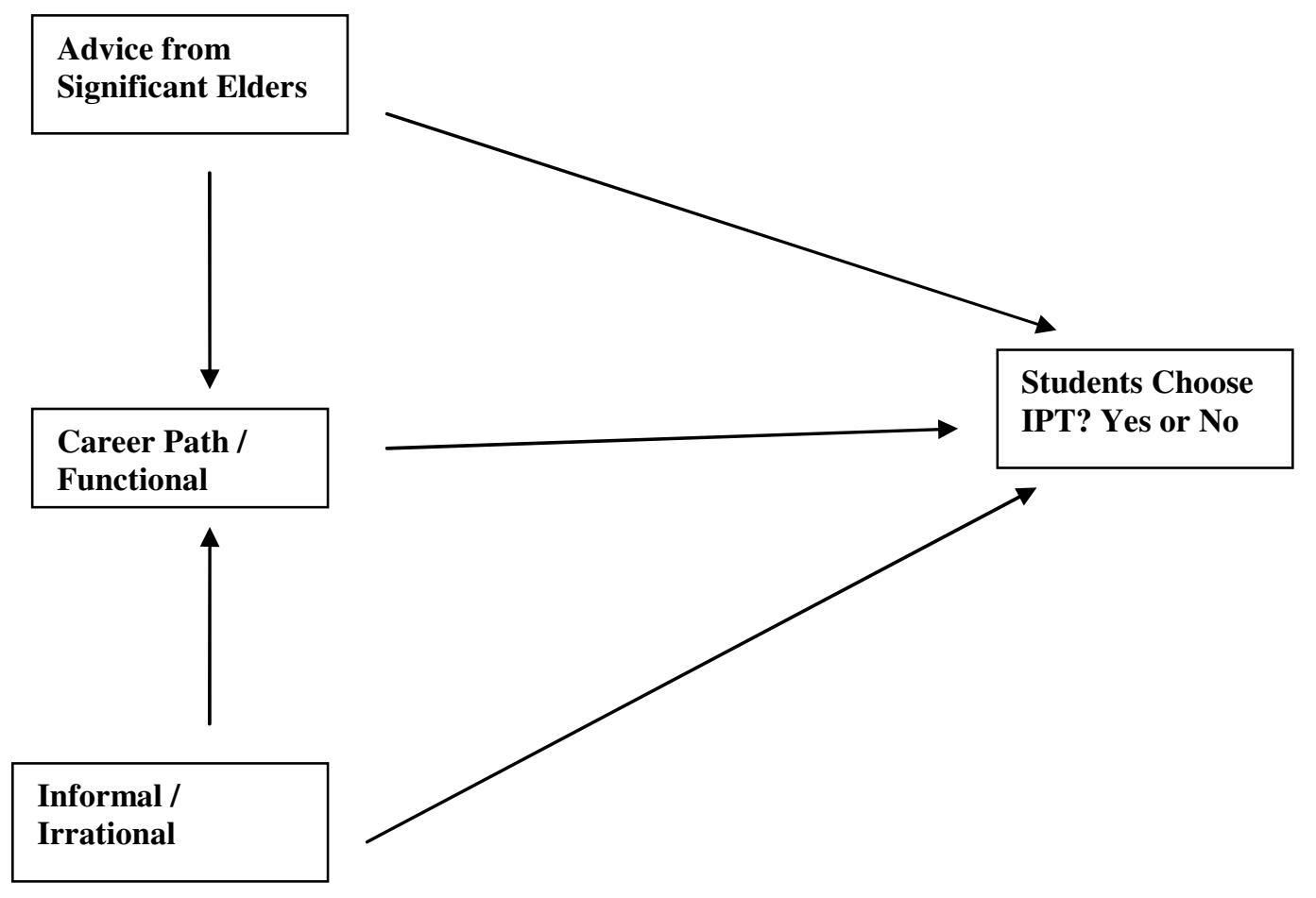

Figure 1: Preliminary research model: Factors influencing students' decision to choose IPT

The results of this study suggest that students are strongly driven by career related issues when it comes to choosing I.P.T. These students are driven more by the extrinsic rewards offered by I.P.T. than by the intrinsic nature of the subject. This is a very important consideration for the I.T. industry, including those involved in training the I.T. professionals of tomorrow. There is little doubt that key attractions of a career in information technology have in recent times been a perceived ready supply of jobs and good salaries. These extrinsic factors related to a career in information technology have lost much of their lustre in the last two to three years. It could thus be that the factors which attracted so many students to I.T. are now acting as disincentives. Of particular concern is the number of potentially strong students who are now attracted to other fields.

While the influence of the career-related variables is beyond question, it must be conceded that the third most influential variable related to the topics in the subject. This variable is clearly associated with intrinsic rewards and motivations but it does not seem to act in concert with other variables. It is correlated with the apparently unrelated variables influence of friends and line on the selection form on which I.P.T. appears. Both of the latter variables are substantially less powerful than the topics variable.

We expected significant gender differences as regards the reason for choosing I.P.T. but were surprised to find a significant difference on only one variable and a tendency towards significance for a second. When the two variables involved are examined in more detail an interesting gender difference does emerge. Males were significantly more influenced than females by issues directly related to future career, while females did appear to be more influenced than males by a direct interest in the topics involved in the subject. We argue that this does not mean females are more interested in I.P.T. as a subject than males. Rather, it suggests that those females who chose I.P.T. were driven more by intrinsic motivators than their male counterparts. The evidence for this is not very strong, however, and we hope to build on it during the next phase of our research. 
Our findings indicate a substantive degree of rational thinking and maturity in the decision making process. These students would appear to be balancing the advice of parents and career guidance officers with their own research into career options, curriculum content and the importance of a good O.P. Paradoxically, this rational behaviour is offset by a degree of irrationality. Some students are influenced strongly by their friends, the perceived reputation of the teacher or simply the line on which IPT appears on the selection form. There appears to be some students, particularly those who use the 'line' method, whose decision is largely random. We suggest that these students have limited information about the options available to them and require appropriate information and advice.

This research is exploratory and further work is required to validate and confirm the reliability of the preliminary research model. In particular, the number of items in the questionnaire will be expanded in order to validate and possibly expand the underlying factors identified in this study. We will also develop a more comprehensive instrument to measure students' attitudes. The influence of peers and irrational elements will also be examined in more detail.

In conclusion, this research would suggest that students in regional / rural Australia apply a relatively rational process when making decisions about taking IPT. This should encourage those involved in the formulation of appropriate policies and programs but they should not ignore the influence of irrational processes and peer groups. Of most significance, this research indicates that students are highly influenced by extrinsic factors when it comes to choosing I.P.T. We argue that this is an important reason for the declining numbers of students who are choosing to take I.P.T. at school or information technology at university.

Given the apparent influence of future career as a motivating factor in students' decision to choose IPT, the authors would suggest that students be provided with specific information on the wide variety of careers which are open to people with IT qualifications, at a time when they are gathering and processing information in order to make their subject selections for Years 11 and 12. Widening the perception of the types of careers available, might well be an influencing factor in the decision making process. This may involve professional development for Guidance Officers and/or guest speakers from industry.

\section{References}

Ainley, J., Jones, W. \& Navaratnam, K.K. (1990). Subject choice in senior secondary school, Canberra. Canberra, Australian Government Publishing Service.

Ainley, J., Robinson, L., Harvey-Beavis, A., Elsworth, G., \& Fleming, M. (1994). Subject choice in years 11 and 12. Canberra: Australian Government Publishing Service.

Campbell, J. \& McMeniman, M. (1982). A comparative study of mainstream courses at Year 11. Canberra, Australian Government Publishing Service.

Furlong, A. \& Cartmel, F. (1995). Aspirations and opportunity structures: 13-year-olds in areas with restricted opportunities. British Journal of Guidance and Counselling. 23, 361-375.

Mann, L., \& Harmoni, R. (1988). Effectiveness of the GOFER course in decision making for high school students. Journal of Behavioral Decision Making, 1, 159-168.

McBryde, B. (1991). Year 11 Subject selection: Issues and trends. Research Report 1. Brisbane, Tertiary Entrance Procedures Authority.

Ormond, C. L. \& Luszcz, M. (1991). A metacognitive analysis of decision making in adolescence. Journal of Adolescence, 14, 275-291.

Preece, P. F. W. (1983) The qualitative principle of teaching. Science Education, 67, 69-73.

Students shun IT in downturn. (2002, December 17). The Australian. 
Taylor Fitz-Gibbon, C. (1999). Long Term Consequences of Curriculum Choices with Particular Reference to Mathematics and Science. School Effectiveness and School Improvement, 10 (2).

Warton, P. M. \& Cooney, G. H. (1997). Information and choice of subjects in the senior school. British Journal of Guidance \& Counselling, 25.

\section{Biographies}

Glen Van Der Vyver is a senior lecturer in Information Systems at the University of Southern Queensland. He worked at the "coalface," in Human Resources and IT (mostly), for around fifteen years before becoming an academic. He leads the database "stream" and teaches the core database courses. Glen has a varied academic background and research interests, ranging from core interests relating to risk perception, information technology careers, teaching IT e-business to more personal interests in literature, art history and film.

Debbie Crabb is a lecturer in Information Systems at the University of Southern Queensland. Debbie teaches in the Systems Analysis and Database Design areas as well as the final year computing project course. Debbie has a Bachelor of Information Technology, a Graduate Diploma of Education and a Master of Education Technology. Debbie has had experience in the IT industry as an analyst programmer and as an educator in both secondary and tertiary education. Her main research interests are in the areas of IT education, IT careers and gender issues in IT.

Michael Lane is a lecturer in the Division of Information Systems, Faculty of Business, University of Southern Queensland. He holds an Honours in Information Technology from the same university and recently completed a PhD with a focus in E-Commerce Development. He has published widely in Information Systems and Electronic Commerce and has varied interests in research and teaching. He has run a postgraduate course on E-Business Strategy at the Australian Graduate School of Business at USQ for the last four years. 